\title{
EQUITY EVALUATION OF URBAN PARK SYSTEM: A CASE STUDY OF XIAMEN, CHINA
}

\author{
Tao LUO ${ }^{\mathbb{D}}$, Fengmei YANG, Lianglong WU, Xihong GAO $\mathbb{B}^{*}$ \\ School of Architecture and Urban Planning, Fuzhou University, Fuzhou, China
}

Received 14 November 2019; accepted 06 February 2020

\begin{abstract}
Highlights
This study proposes an indicator, area- and population-weighted park service level, to quantitatively assess the equity of urban park services.

In this case study, inequity in the provision of urban park services, presented by the huge difference in park service level enjoyed by urban residents, was found between different geographical regions (island and mainland) and different administrative regions (six administrative regions).

> It was found that the equity in urban park service varies depending on the scale, as for the spatial correlation between urban park service level and population density. It is noted that the existing of an obvious urban center seems to be the precondition of a significant correlation between population density and park service level.
\end{abstract}

\begin{abstract}
Urban parks play a distinctive and important role in satisfying residents' demands on leisure and recreation, and thus have become the focus of research in the field of urban planning and sustainable development. This paper used equity as indicator to combine both the supply and demand sides of urban park service. Taking Xiamen as the study case, the relationship between spatial distribution of population and park services was analyzed. The results show that while population density has a significant spatial relationship with urban park service level at the city scale, Xiamen has the problem of neglecting the equity of urban park service between people and regions within the city. The proposed approach builds up the linkage between urban park service and urban population in order to evaluate the performance of urban park. Although the mechanism remains to be discussed, this study provides a useful auxiliary tool for constructing a guideline for urban green space planning, since urban park is increasingly seen as a kind of restricted public resource and ensuring its equity should be an important task for city mangers.
\end{abstract}

Keywords: urban park, green space, scale effects, spatial distribution, equity, supply-demand balance.

\section{Introduction}

Among all the forms of urban green space, urban parks play a distinctive and important role since they occupy a large acreage and offer very complete functions in satisfying residents' demands on leisure and recreation (Aida et al., 2016; Shen et al., 2017; Xie et al., 2018). In particular, urban parks can mitigate the urban heat island effect and thus greatly improve the outdoor thermal environment in the background of the ongoing global warming (Yan et al., 2018), increase the degree of enjoyment and satisfaction for urban residents (Razak et al., 2016). As a consequence, in recent years, more attention has gradually been paid to the planning, construction and management of urban parks. Studies on performance evaluation of urban park systems are becoming a hotspot in scientific research (Brown et al., 2018; Deutscher et al., 2019). Among all the research perspectives, the equity of park service, in particular, is of great significance to urban planning considering the multiple services that parks can offer to surrounding residents (Tan \& Samsudin, 2017; Rigolon, 2016).

In the previous literatures, studies on public service equity experienced three stages, from territorial equality, spatial equity to social equity (Jiang et al., 2011; Xiao et al., 2017). Territorial equality emphasized that every resident in the city should have the same opportunity to enjoy the service. Homogeneous spatial distribution and

${ }^{*}$ Corresponding author. E-mail: xihonggao@126.com 
territorial justice were the core concepts of this stage. Territorial equality at this stage did not take the actual spatial layout of facilities with their surrounding condition, the needs of people and the benefits of services into account (Lineberry, 1977; Rich, 1979). In the stage of spatial equity, the concept of accessibility began to appear and people began to pay attention to the economic efficiency of public service (Talen \& Anselin, 1998). Social equity takes social factors affecting people's needs into account, such as age, religion and needs of audiences (Boone et al., 2009).

Nowadays, cities use high-quality park systems to attract tourists and residents (Paulo et al., 2013). It was found that differences in fiscal capacity can result in disparities in park provision (Smith \& Floyd, 2013), and inequity was reported in many cities worldwide in terms of the acreage, quality and safety of urban parks (Boone et al., 2009; Rigolon et al., 2018; Donaldson et al., 2016). Studies in the cities from the USA, England, Germany and Australia, showed that low-income ethnic minority people tend to live in closer proximity to parks than wealthier white people, while the latter are at an obvious advantage in terms of park acreage, quality, safety and per capita possession (Wüstemann et al., 2017). Some studies tried to compare park classifications with neighborhood social characteristics to find out what kind of people have access to what kind of parks (Ibes, 2015). The reported inequities in park provision are normally showed close relationship to socioeconomic and ethnic factors (Tan \& Samsudin, 2017; Boone et al., 2009; Rigolon et al., 2018). In addition, the effects of scale on park provision and spatial equity were also assessed in Asian cities, such as Singapore (Tan \& Samsudin, 2017). In general, existing studies show the complexity of influencing factors of service equity in urban parks (Brandli et al., 2015).

In China, a current investigation at the national level, based on panel data from 258 Chinese cities, found wealthier cities have higher green space coverage and better urban park services than less affluent cities (Chen et al., 2017). The planning and evaluation of urban park indistinguishably takes urban green land per capita, percentage of greenery coverage and greening rate to serve as indexes, which does not take the population distribution and human needs into account, and has limitations in measuring and coordinating the fairness of urban green space (Yang et al., 2019). There have been many related research reports to calculate the accessibility of park green space based on population distribution (Higgs, 2012; Lee \& Hong, 2013), but these studies usually assumed that the population is evenly distributed in statistical units, which affects the reliability of the evaluation results to a certain extent (Chen et al., 2016). This study uses population density data to avoid the inadequacy of treating populations in statistical units as homogeneous distributions. In order to combine both the supply and demand sides of urban parks, this paper understands the equity as an index indicating whether urban residents have the same opportunity to enjoy the same quality and quantity of park services and as an index representing the spatial relation between park services and population. Taking Xiamen City as the study case, using population density data, which is accurate to the settlement, and combines the distribution of population and park services to discuss the equity of urban park services under the perspective of the supply-demand balance.

\section{Methods}

\subsection{Overview of the study area}

The study area, Xiamen, located in the southeast of Fujian province, is a port and scenic tourist city along the coast facing the Taiwan Strait. According to 2016 statistics, at the end of 2015, the land area of Xiamen was $1699.39 \mathrm{~km}^{2}$. The area of urban construction land, i.e. land for residential buildings and public facilities, land for industrial and mining purposes, land for transportation and water conservancy facilities, land for tourism and land for military facilities, added up to $456.27 \mathrm{~km}^{2}$.

The jurisdiction area of Xiamen is separated by the sea (Figure 1), forming two different geographical parts of Xiamen Island (XI) and Xiamen Mainland (XM). XI, which accounts for $9.28 \%$ of the area but $51.94 \%$ of the total population of the city, consists of two administrative districts, Siming and Huli. XM includes four administrative districts, i.e. Haicang, Jimei, Tong'an and Xiang'an (Figure 1). In general, there exist economic differences between XI and XM. XI is more densely settled and economically developed than XM.

\subsection{Data source and preprocessing}

The data used in the study includes the "Edition and Modification of the Green Space System of Xiamen City and the Delineation of the Green Line System", which was developed in 2015 (Xiamen Urban Planning and Research Institute, 2015), the "Xiamen population density data in 2015", the "Xiamen administrative map" and the "20102020 revision of Xiamen urban master plan".

\subsubsection{Park classification and distribution}

In the "Edition and Modification of the Green Space System of Xiamen City and the Delineation of the Green Line System", urban parks are classified into five categories, i.e. comprehensive park (Comp.-P), community park (Comm.-P), linear park (LP), special park (SP) and green space along the street (GPAS). Comm.-Ps are further divided into residential area parks (Comm.-P1) and residential community parks (Comm.-P2) according to their sizes.

GPAS includes small green land along the street and green squares in the street, and has normally a small area and a relatively weak public service capacity, so is not considered in this paper. In this study, LPs are further classified into Comp.-P or Comm.-P1 depending on their sizes, in order to assign LPs a service radius, which cannot be found through literature review. In total, there are 


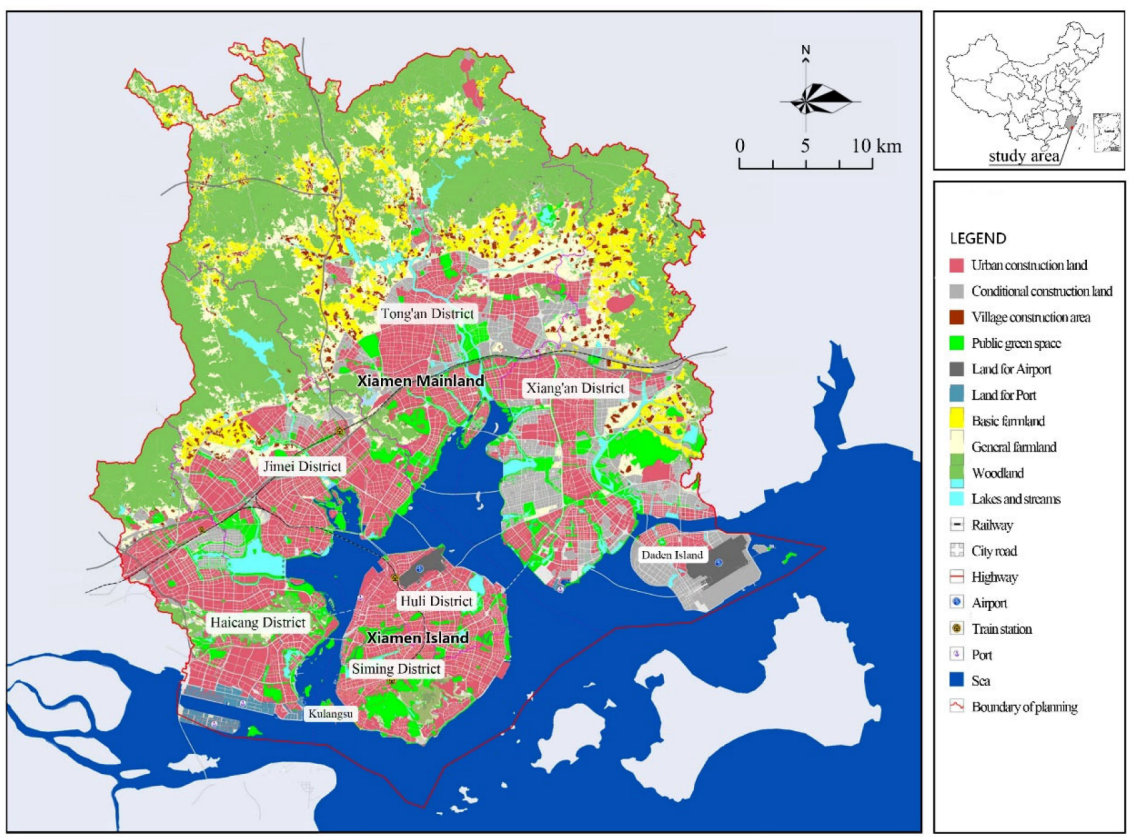

Figure 1. Geographic location and planned land use of Xiamen (source: Xiamen Planning Commission, 2009)

four park categories used in this study, i.e. Comp.-P, SP, Comm.-P1 and Comm.-P2 (Table 1).

According to the "Edition and Modification of the Green Space System of Xiamen City and the Delineation of the Green Line System", the service radius of Comp.-P is 2000 meters, Comm.-P1 has a service radius around $800-1000$ meters, and the service radius of Comm-P2 is $300-500$ meters. However, the service radius of SP is not clearly defined. Since SPs are defined as the green space with specific content and form, and have certain recreational facilities, and the facilities and landscape quality of SP are generally higher than GPAS and LP (Yi \& Bai, 2016), the service radius of $S P$ is assigned as 1000 meters in this study. In addition, the parks equipped with complete facilities and comprehensive service have relatively higher attraction and, accordingly, larger service radius, so the parks are assigned with different service levels according to their service capacity, Referred to Chen et al. (2016), Comp.-P is assigned a value of $4, \mathrm{SP}$ is assigned a value of 3, Comm.-P1 is assigned a value of 2, and Comm.-P2 is assigned a value of 1 . (Chen et al., 2016). Table 1 shows the service radius and assignments of various parks.

As shown in Table 1, in 2015, there were 104 parks in Xiamen. The total area of these parks is $23.90 \mathrm{~km}^{2}$, accounting for $1.41 \%$ of the total area of the study area. It is noted, that Xiamen has more parks with higher service level than that with lower service level. XI is smaller in size than XM, but has more parks.

Table 1. Number of parks within each district in Xiamen in 2015, service radius and assignments of various parks (Chen et al., 2016; Yi \& Bai, 2016)

\begin{tabular}{|c|c|c|c|c|c|c|}
\hline & \multirow{2}{*}{ District } & \multicolumn{4}{|c|}{ Type of parks } & \multirow{2}{*}{$\begin{array}{c}\text { Total } \\
\text { number }\end{array}$} \\
\hline & & Comp.-P & SP & Comm.-P1 & Comm.-P2 & \\
\hline \multirow{6}{*}{$\begin{array}{l}\text { Number of } \\
\text { parks }\end{array}$} & Siming & 7 & 15 & 9 & 7 & 38 \\
\hline & Huli & 11 & 5 & 5 & 1 & 22 \\
\hline & Haicang & 3 & 2 & 3 & 1 & 9 \\
\hline & Jimei & 6 & 6 & 4 & 1 & 17 \\
\hline & Tongan & 2 & 3 & 3 & 1 & 9 \\
\hline & Xiang'an & 4 & 0 & 5 & 0 & 9 \\
\hline \multicolumn{2}{|c|}{ Total number } & 33 & 31 & 29 & 11 & 104 \\
\hline \multicolumn{2}{|c|}{ Service radius $(\mathrm{m})$} & 2000 & 1000 & 800 & 500 & \\
\hline \multicolumn{2}{|c|}{ Service level } & 4 & 3 & 2 & 1 & \\
\hline \multicolumn{2}{|c|}{ Notes/description } & $\begin{array}{l}\text { Includes LPs } \\
\text { bigger than } 10 \\
\text { hectares }\end{array}$ & $\begin{array}{l}\text { Green space with specific } \\
\text { content and form, with } \\
\text { certain recreational } \\
\text { facilities }\end{array}$ & $\begin{array}{l}\text { Community parks bigger } \\
\text { than } 1 \text { hectare and includes } \\
\text { LPs smaller than } 10 \\
\text { hectares }\end{array}$ & $\begin{array}{l}\text { Community } \\
\text { parks smaller } \\
\text { than } 1 \text { hectare }\end{array}$ & \\
\hline
\end{tabular}




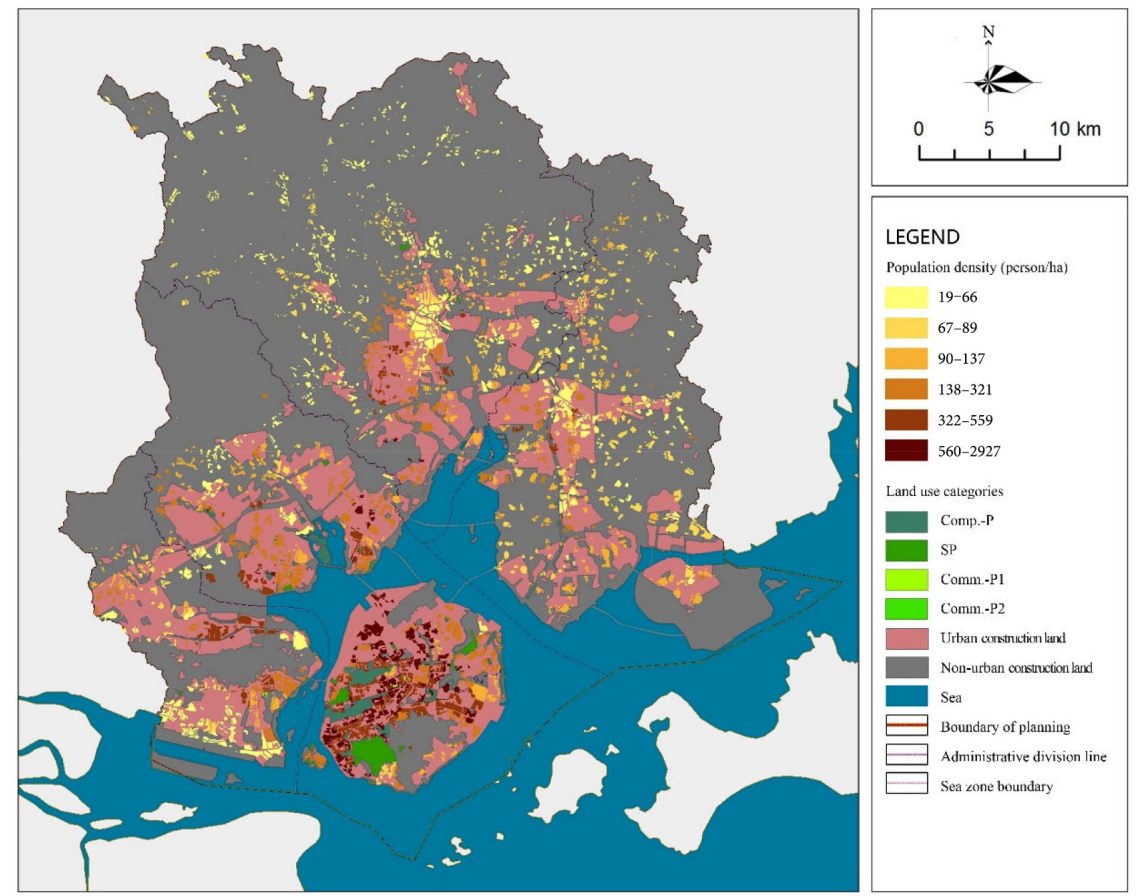

Figure 2. Park service area in Xiamen

Using the buffer tool in ArcGis, the land area covered by park service is calculated and showed in Figure 2. The total land area with park service supply adds up to $422.45 \mathrm{~km}^{2}$, accounting for $24.86 \%$ of Xiamen's land area. Among them, around $55.55 \%$ of the urban construction area $\left(253.49 \mathrm{~km}^{2}\right)$ is covered by park service.

\subsubsection{Population density}

The population density data of Xiamen used in the year of 2015 is provided by the Chinese Academy of Sciences.
This data describes the population density in each residential community (Figure 3). According to this data, the whole population in Xiamen is 3,470,800, of which 2,767,000 (about 79.72\%) are within the urban construction area (Figure 3). The residential communities with high population density (56000-292700 people $/ \mathrm{km}^{2}$ ) are mainly located in the west of XI. Those with much lower population density (1900-6600 people $/ \mathrm{km}^{2}$ ) are mainly distributed in XM and out of the urban construction area. According to the "Yearbook of Xiamen Special Economic

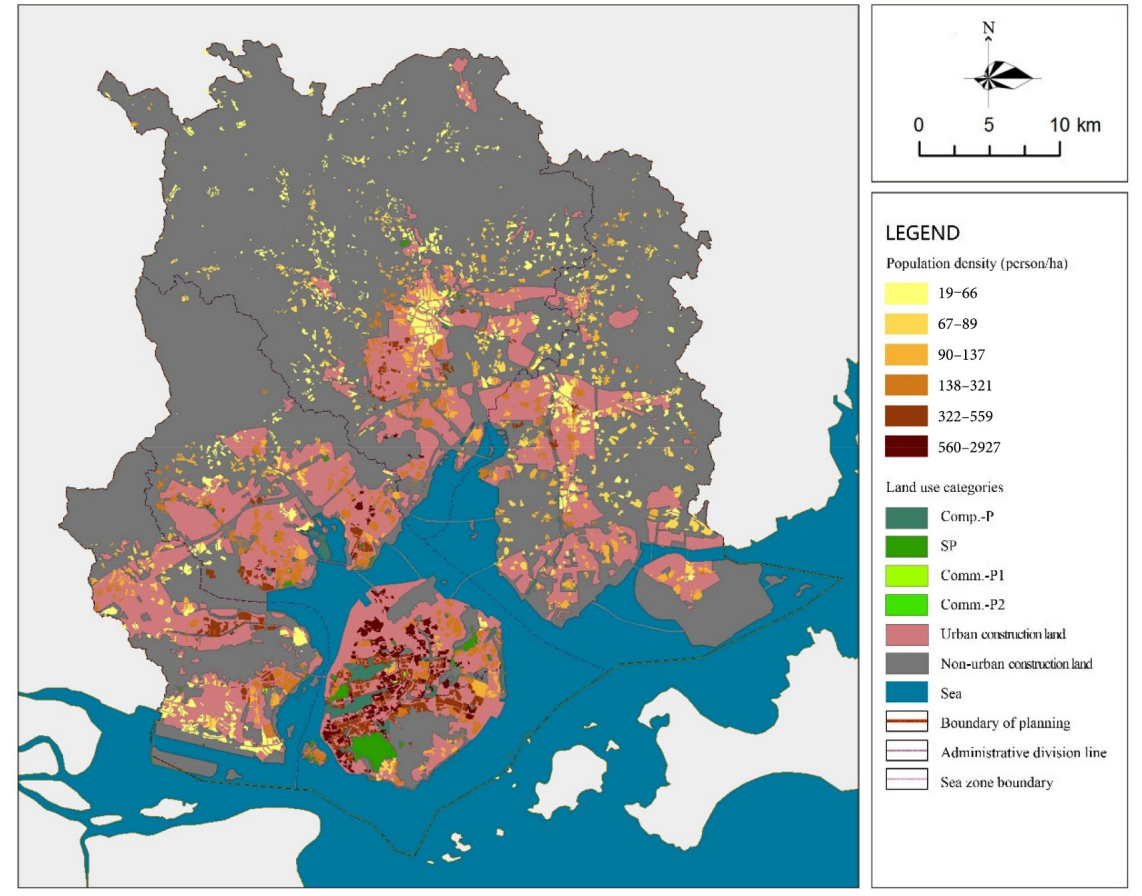

Figure 3. Population distribution in Xiamen 
Zone 2015” (Xiamen Statistics Bureau, 2015), the total permanent population of Xiamen is 3860000 , which is around 390000 (approx 10.10\%) more than the population calculated using the data from Chinese Academy of Sciences.

\subsection{Analysis method}

To reflect the average level of park service in Xiamen, the area-weighted and population-weighted park service levels are calculated.

Firstly, the area-weighted park service level is calculated using the equation as follows:

$$
R=\frac{\sum\left(S_{i} \times A_{i}\right)}{A_{t}}
$$

In formulate (1), $R$ refers to area-weighted park service level of a calculation area. $S_{i}$ refers to the added service level of different parks covering the residential community $i . A_{i}$ and $A_{t}$ refer to the acreage of residential community and the total area of the calculation area. When the calculation area is the entire city, At is the whole areas within the entire city. When the calculation area is the urban construction area, At is the residential areas within the urban construction area.

Secondly, the pop-weighted (pop-weighted) park service level is calculated in the same way. The equation is as follows:

$$
P=\frac{\sum\left(S_{i} \times P_{i}\right)}{p_{t}} .
$$

In equation (2), $\mathrm{P}$ refers to pop-weighted park service level of a calculation area, $S_{i}$ refers to the added service level of different parks covering the residential community $i . P_{i}$ and $P_{t}$ refer to the population in the residential community $i$ and the total population in the calculation area. When the calculation area is the entire city, $P_{t}$ is the sum population within the whole city. For the urban construction area, $P_{t}$ is the sum population within urban construction area.

Finally, the relationship between the spatial distribution of population density and park service level is analyzed using Spearman correlation analysis. Based on this, the per capita supply levels of park service were calculated using the equation as follows:

$$
S_{\text {per captia }}=\frac{S_{i}}{D_{i}} \text {. }
$$

In formulate (3), Sper capita refers to per capita supply level of park services. $S_{i}$ and $D_{i}$ refers to the added park service level and population density in the residential community $i$.

\section{Results}

\subsection{Equity of park service analyzed without consideration of population}

\subsubsection{The spatial distribution of park service}

Distribution of park service levels in Xiamen is drawn in Figure 4. The areas with high level park service in XI are mainly along the city main road which goes across the island from the south-western to the north-eastern and connects to Xiang'an District in XM. This main road is recently built up and plays a key role in the transportation between XI and XM. The areas with high level park service in Haicang and Jimei districts are mainly along the coastline. These two districts were mainly developing along the coastline in the history. In Tongan district, these

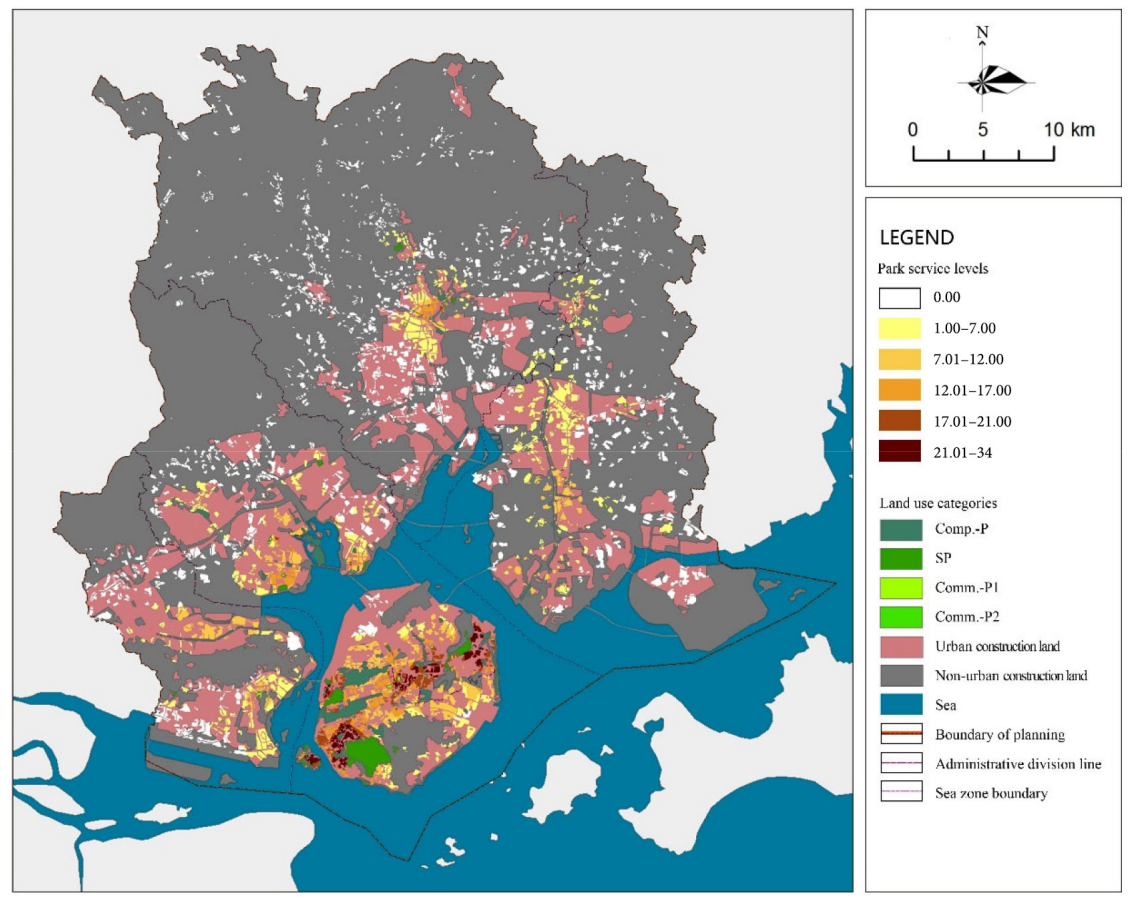

Figure 4. Distribution of park service levels in Xiamen 
areas are distributed mostly around the district center. In the past, the district center played an import role in Tong'an district. While in Xiang'an district, the situation is similar with those on XI, the areas with high level park service are significantly along the main road of the district. In general, distribution of park service in Xiamen are the results of the development history of the city (mainly in XM), or because of the recent development planning (mainly in XI).

\subsubsection{Residential community covered by different levels of park service}

The total residential area of Xiamen, the sum area of all residential communities, is $163.74 \mathrm{~km}^{2}$. The residential area covered by park service is $84.70 \mathrm{~km}^{2}$, accounting for $51.73 \%$ of the total residential area of Xiamen. The residential area within urban construction area is $98.63 \mathrm{~km}^{2}$, among them, $69.6 \mathrm{~km}^{2}$ (about 70.62\%) is covered by park service.

According to formula (1), the area-weighted park service level of Xiamen can be calculated as 4.63 (Figure 5). The residential communities with park service level higher than the average account for $29.96 \%$ of the total residential area of Xiamen. The area-weighted park service level in urban construction area is 6.74. The area with park service level higher than the average is $41.35 \mathrm{~km}^{2}, 41.92 \%$ of the residential area in urban construction area.

It can be seen from Figure 5, the area distribution of each assignment at the city level and the urban construction area level is basically the same. When the park service level is higher than 12 , the residential area of each assignment in the urban construction area is basically the same as that of the city, indicating that the residential areas with high levels of park service mainly locate in the urban construction area.

\subsection{Equity of park service analyzed with consideration of population}

\subsubsection{Population covered by different levels of park service}

Figure 6 shows the quantitative distribution of population with different park service levels, from no service to the highest service level of 34 . About $71.00 \%$ of the total population of Xiamen, around 2,464,400 people, is supplied with park service. Among them, about nine out of ten live in the urban construction area. Over half (54.08\%) of the people without park service live in urban construction area. Meanwhile, 241,700 (only 34.34\%) out of 703,800 people, who live outside urban construction area, are covered by park service.

According to formula (2), the pop-weighted park service level in Xiamen is 8.05 (Figure 6). It means that, in average, the residents of Xiamen can enjoy a service equals to two comprehensive parks. About $35 \%$ of the total population is supplied with a park service even better than the average. The pop-weighted park service level in urban construction area is assigned 9.34. Among the residents living in urban construction area, 1,198,400 (43\%) out of 2,766,900 people enjoy a park service better than the average.

The distribution of population covered by different levels of park service in Xiamen, illustrated in Figure 6, showing the distribution pattern basically in accordance with the Gaussian Distribution Curve, only population with service level of 4 and 8 are extremely high. The quantity structure of urban park in Xiamen showed in Table 1 might shed light on the explanation of the strange distribution. Unlike a normal retail network, Xiamen's park network consists of more high-class parks than low-class ones. There are more comprehensive parks in Xiamen and they offer an obvious larger service area. When the

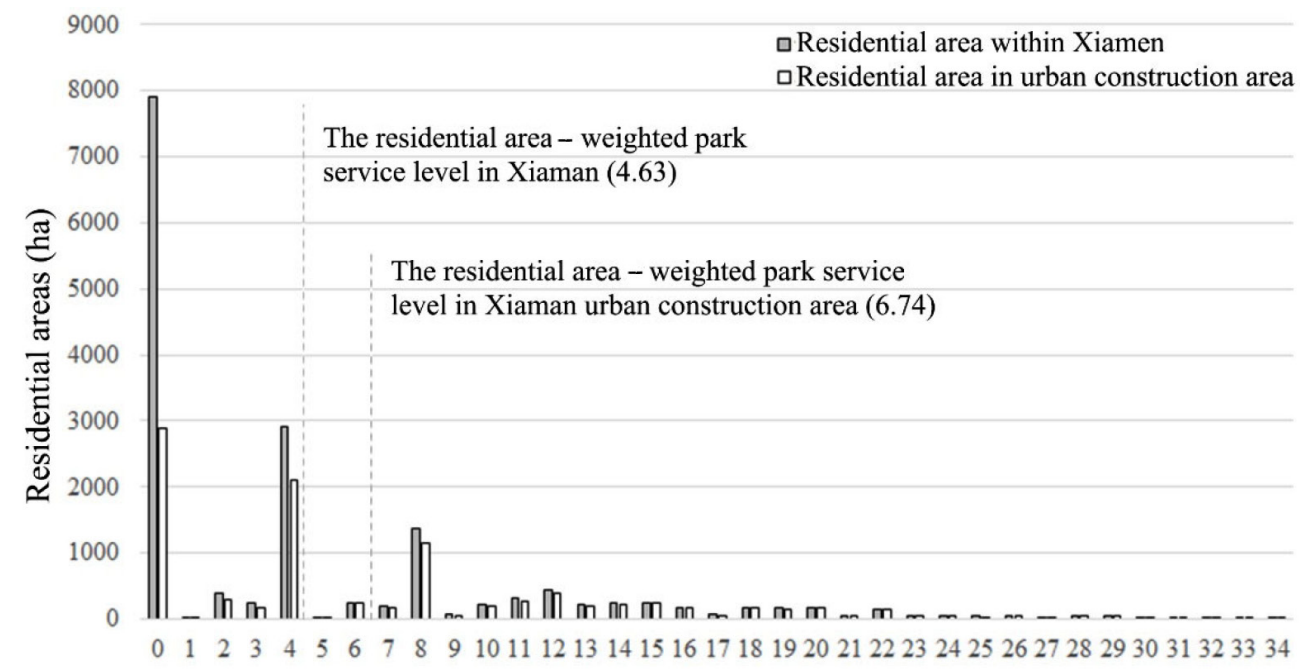

Park service levels

Figure 5. Distribution patterns of residential area covered by different levels of park service 
population is covered by one or two comprehensive parks, the service level is 4 or 8 .

The distribution pattern of population with different park service levels in urban construction area is highly similar with the whole city. In particular, when the service level is above 12 , the population covered by different service levels is basically the same both in the urban construction area and the whole city, indicating that the population enjoys the high-class park service are mainly within urban construction area.

\subsubsection{Equity between regions}

According to the geographical form of Xiamen City, the park service capacity is further compared between XI and $\mathrm{XM}$. It can be seen from Figure 7a that the average park service level in XI is 12.94 , the highest level is 34 . The average park service level in XM is 2.97 , the highest level is 18 . The average park service level of $\mathrm{XI}$ is 4.35 times higher than that of XM. While in Figure 7b, the average park service level in XM urban construction area is 3.64, and the average park service level in XI urban construction area is $12.88,3.54$ times higher than that of XM. It shows that the island park system is relatively complete.

The distributions of population covered by different park service level in XM and the Xiamen city have the same trend. That is, the population with the assignment of 0 has the largest number, followed by 4 , and finally 8 . The population distribution of XI is the opposite of Xiamen city, the population with the assignment of 8 has the largest number, followed by 4 , and finally 0 .

As can be seen from Figure 7, the park service level in $\mathrm{XI}$ is relatively high, which can be up to $24-34$, means the park facilities on the island are relatively complete. A large number of residential communities outside urban construction area do not have park services, the population densities and population without park service are not high (the total population is 462,100 ). Most of the residential communities which do not have park services are mainly distributed in XM like Tongan District, Jimei District, and Haicang District.

\subsubsection{Equity between administrative districts}

Park service capabilities are also compared according to administrative divisions. It can be seen from Figure 8 that the park service levels of the two administrative districts in XI are more diversified. The park service levels of the four administrative districts in XM are mainly in a certain value rage, and there are quite a few people who do not receive park service. Specifically, $85.49 \%$ of the population in Tongan District, $48.85 \%$ of the population in Xiang'an District, $41.10 \%$ of the population in Jimei District and $28.64 \%$ of the population in Haicang District do not receive park services.

Population without park services in urban construction areas accounts for a relatively high percentage of population in urban construction land. The number in Tong'an District is $80.89 \%$, in Jimei District is $31.23 \%$, in Xiang'an District is $29.82 \%$ and in Haicang District is $24.21 \%$.

The average park services of the urban population shows that the park service enjoyed by the two administrative districts of XI are much higher than those of XM, indicating that the park facilities on the island are more complete. The highest and average park service level, as well as average park service level of urban construction area in Siming district is the highest, while those in Tong'an and Xiang'an districts are low. Total park acreage between each district is also of a big difference. In general, the average value of each administrative area in XM is significantly lower than XI, indicating the lack of park facilities in XM.

The summary of the analysis results of each administrative district are shown in Table 2. It can be seen from Table 2 that the highest level of park service, average park

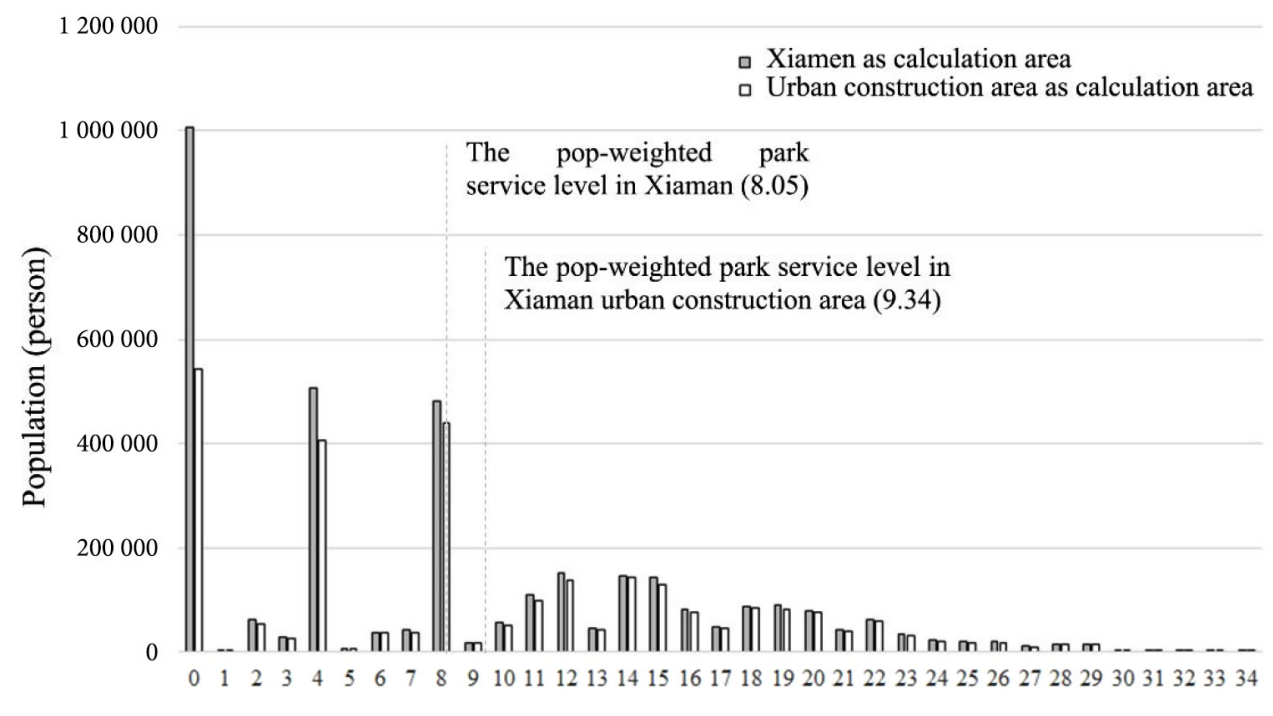

Park service levels

Figure 6. Distribution patterns of population covered by different levels of park service in Xiamen 


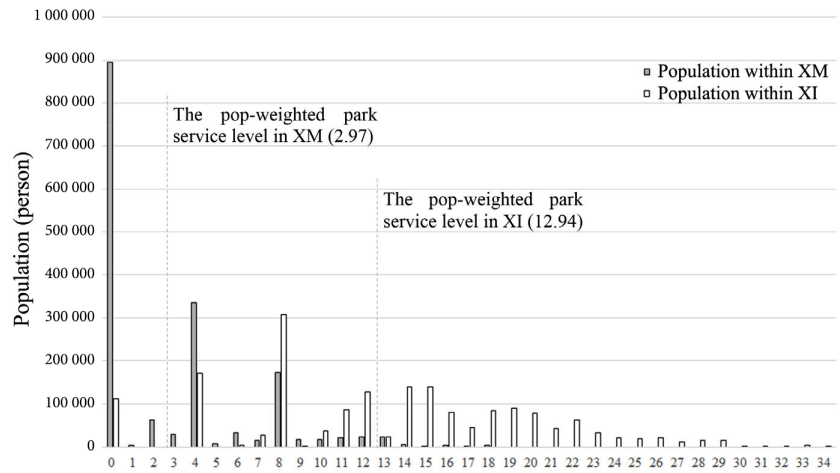

Park service levels

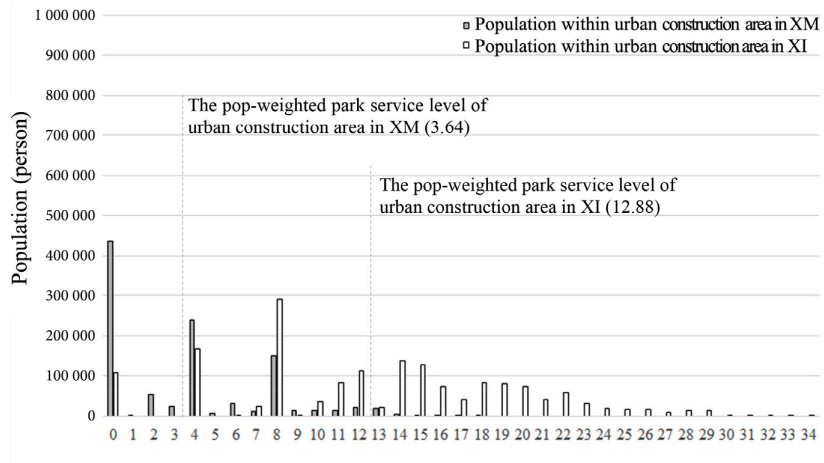

(a) XM and XI as calculation area

(b) Urban construction area in XM and XI as calculation area

Figure 7. Distribution patterns of population covered by different levels of park service in comparison between XM and XI
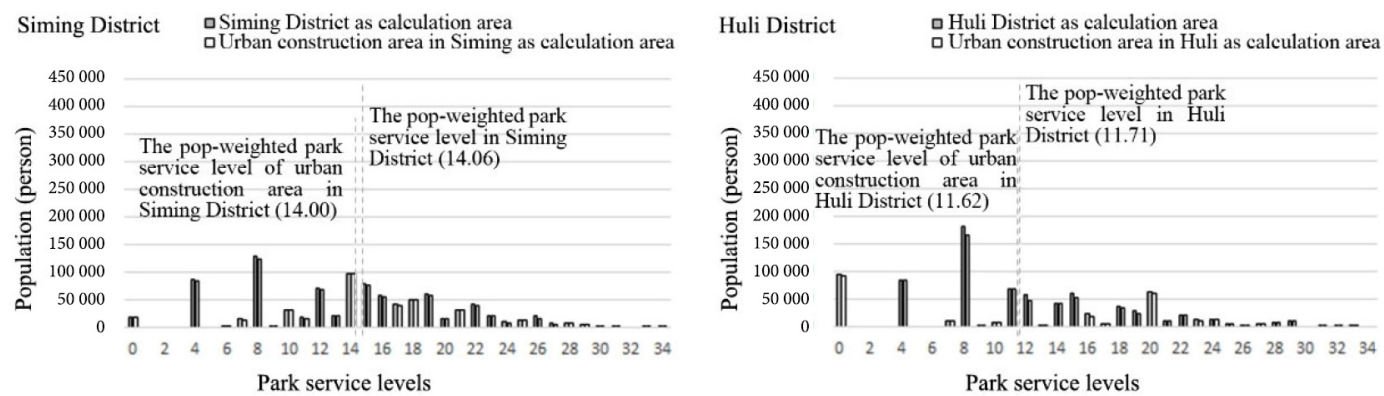

Haicang District $\square$ Haicang District as calculation area
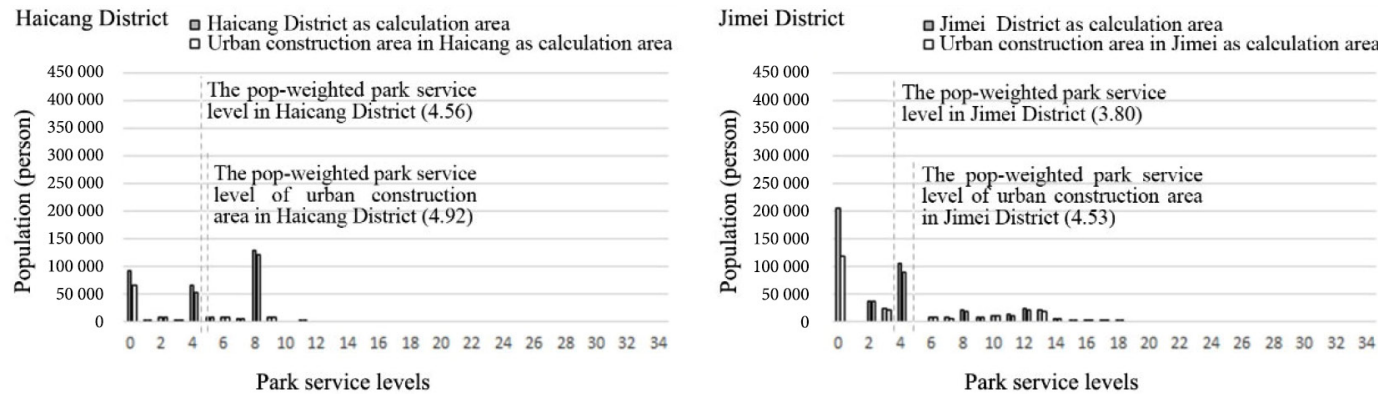

Tong'an District $\quad$ Tong'an District as calculation area

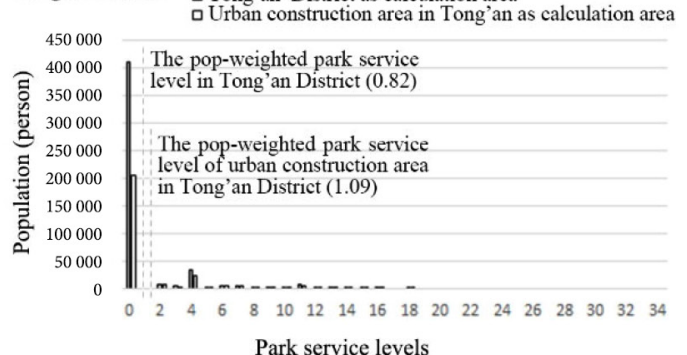

Xiang'an District $\mathrm{aXiang}$ 'an District as calculation area

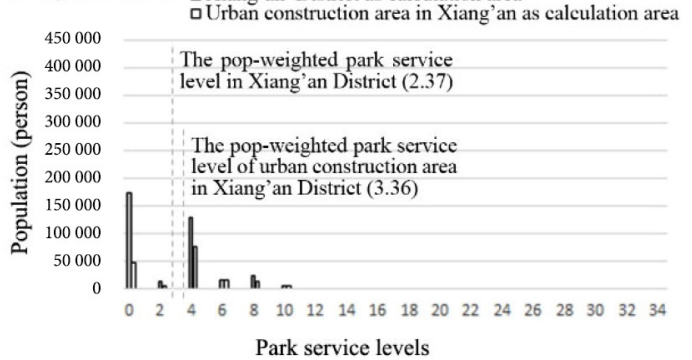

Figure 8. Comparison of population of each district and urban construction area covered by different levels of park service 
service, average park service level of urban construction area in Siming district are the highest. Tong'an District has large land acreage, small park acreage and a relatively small population with park service. The average park service level in both whole district and the urban construction area are the lowest. Meanwhile, the highest level of park service in Xiangan district is the lowest.

\subsubsection{The relation between park service and population}

Pearson linear correlation analysis was carried out for residential population density and park service level. The correlation coefficient test was tested by two-sided test. The results show that there exists a significant correlation between the two variables $\left(\mathrm{R}^{2}=0.1264, \mathrm{p}<0.01\right)$ at the city scale. As shown in Figure 9, the population densities of the residential communities without park service are relatively low, but the abnormal values with the highest population density appear. The outliers appear on the upper edge, so that the average population density is higher than the median population density.

In the whole city, residential communities with high population density generally have a higher level of park service. However, when the city is divided into two samples, XI and XM, the results show that a significant positive correlation between residential population density and park service level only exists in XM. Besides, when the sample, XM is further divided into four administrative districts and analyzed separately, only the service level of HaiCang District has a significant positive correlation with residential population density. The analysis results of XI show no correlation, but there are significant positive correlations in the two administrative districts Siming District and Huli District separately (Table 3 ). The reasons for this will be discussed in the discussion section.

Table 2. Comparison of park service capacity between each district

\begin{tabular}{|l|c|c|c|c|c|c|}
\hline \multicolumn{1}{|c|}{ Administrative district } & Siming & Huli & Haicang & Jimei & Tong'an & Xiang'an \\
\hline Acreage $\left(\mathrm{km}^{2}\right)$ & 83.99 & 73.77 & 186.46 & 274.29 & 699.36 & 411.50 \\
\hline $\begin{array}{l}\text { Population living in urban construction area } \\
\text { (thousand) }\end{array}$ & 908.7 & 797.8 & 269.7 & 383.3 & 253.9 & 153.6 \\
\hline Total population (thousand) & 944.2 & 855.1 & 317.5 & 508.9 & 483.0 & 359.1 \\
\hline $\begin{array}{l}\text { Population in urban construction area with park } \\
\text { service (thousand) }\end{array}$ & 892.0 & 706.4 & 204.4 & 263.6 & 48.5 & 107.8 \\
\hline Population with park service (thousand) & 927.5 & 760.5 & 226.6 & 296.7 & 69.6 & 183.0 \\
\hline Park acreage (km ${ }^{2}$ ) & 11.31 & 5.76 & 1.44 & 2.87 & 0.78 & 1.75 \\
\hline The highest park service level & 34 & 33 & 11 & 18 & 18 & 10 \\
\hline pop-weighted park service level & 14.06 & 11.71 & 4.56 & 3.80 & 0.82 & 2.37 \\
\hline $\begin{array}{l}\text { pop-weighted park service level of urban } \\
\text { construction area }\end{array}$ & 14.00 & 11.62 & 4.92 & 4.53 & 1.09 & 3.36 \\
\hline
\end{tabular}

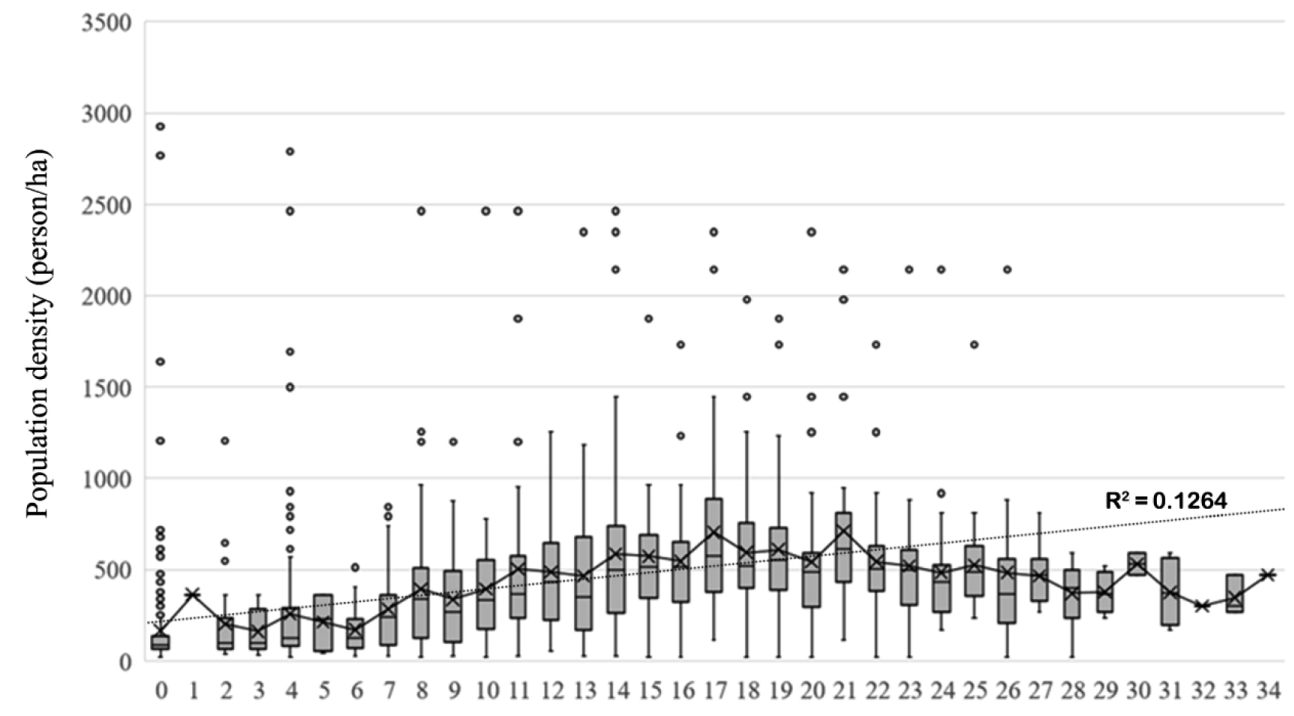

Park service levels

Figure 9. Box plot of the relationship between residential population density and park service levels 
Table 3. Summary of the relationship between residential population density and park service level

\begin{tabular}{|l|l|l|l|l|l|}
\hline Whole city & $\begin{array}{l}\text { positive } \\
\text { correlation }\end{array}$ & XI & no correlation & Siming & positive correlation \\
\cline { 4 - 5 } & & & Huli & positive correlation \\
\cline { 3 - 5 } & & XM & $\begin{array}{l}\text { positive } \\
\text { correlation }\end{array}$ & Haicang & positive correlation \\
\cline { 4 - 5 } & & & Jimei & no correlation \\
\cline { 4 - 5 } & & Tong'an & no correlation \\
\cline { 3 - 5 } & & Xiang'an & no correlation \\
& & &
\end{tabular}

Using formulate (3) the per capita supply level of the park service was calculated and its distribution in Xiamen was illustrated in Figure 10. It was mentioned above that the park service level is generally much higher in the island than that in the mainland. However, it can be seen from Figure 10 that the per capita park service supplies in some parts of XM are basically equal to that in XI. In particular, the per capita park service supplied in the central areas of Jimei, Tong'an and Xiang'an District are higher than the rest areas, and the higher population density results in the lower per capita service supply in XI.

\subsection{Comparison between the equity with and without consideration of population}

Comparing the two kinds of equity illustrated in the section 3.1 and 3.2, it can be seen that the areas with high park service level in Figure 4 are mostly concentrated in $\mathrm{XI}$, which represents the inequity in urban park service. However when population is taken into account, the high per capita park service levels show up both in XI and $\mathrm{XM}$, as illustrated in Figure 10. The per capita park service levels in Jimei District, Tong'an District, and Xiang'an District in XM are as high as that in XI, which means a certain degree increase of equity at the city scale.

The variance of the per capita park service level (0.096) is much lower than that of the park service level (8.322).
It can be seen that after the population density is superimposed, the data distribution of per capita park service levels is more concentrated in a certain scope than the data distribution of park service levels. Therefore, after the population data is taken into account, the equity of park service is increased at the city scale.

\section{Discussion}

In this case study, inequity in the provision of urban park services, presented by the huge difference in park service level enjoyed by urban residents, was found between different geographical regions (island and mainland) and different administrative regions (six administrative regions). Existing studies show the complexity of influencing factors of service equity in urban parks (Brandli et al., 2015). Some articles present that older and denser neighborhoods have better walking access to parks than newer suburban districts, due to the reason that the former were developed to support pedestrian mobility while the latter were planned more likely to be car-dependent areas (Rigolon, 2016). Differences in fiscal capacity can also result in disparities in park provision (Smith \& Floyd, 2013). As for this study case, such inequity in the space pattern of urban parks might be driven by market factors (e.g., real estate prices), government factors (e.g., the division of urban construction zones and the difference in government

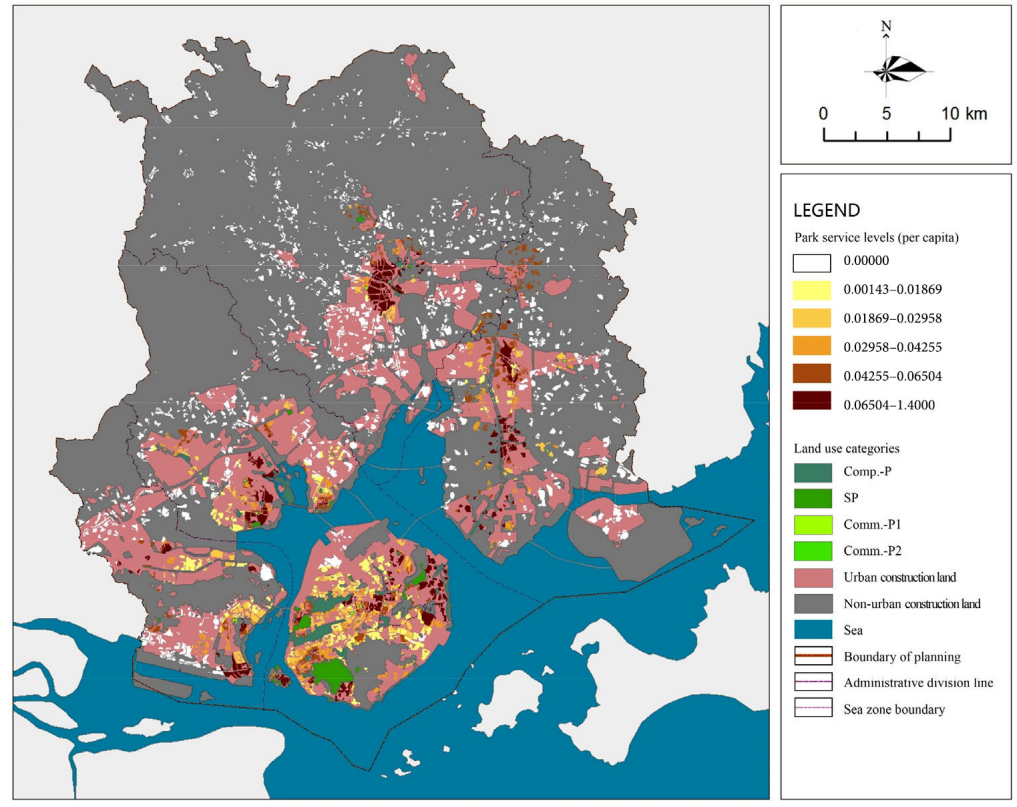

Figure 10. Distribution of per capita park service levels in Xiamen 
investment) and other socio-economic factors. However, this kind of inequity was significantly moderated when the population distribution in the city was taken into account. It is to argue that it is not enough to rely only on the coverage area, when evaluating the equity of public services.

In addition to the conclusions similar to previous studies, there are serious spatial differences in the equity of park green space, and most areas are in an unfair state $(\mathrm{Wu}$ et al., 2016). It was also found in this case study, that the equity in urban park service varies depending on the scale, as for the spatial correlation between urban park service level and population density. It is noted that the existing of an obvious urban center seems to be the precondition of a significant correlation between population density and park service level. For example, the existing of XI as the center of Xiamen leads to a significant positive correlation between population density and park service level at the city scale. XI contains two administrative districts, Siming and Huli, and these two administrative districts have the same development levels. In other words, there is no significant center but two city centers, Siming and Huli, in XI, which contribute to no correlation between population density and residential area density in XI. However, each of the two administrative districts has their own center. Consequently, there is a significant positive correlation between population density and park service level in each of the two administrative districts. Likewise, it shows that Haicang District has formed a city center with matching population and park green space facilities. Meanwhile, park layout of the other three administrative districts in $\mathrm{XM}$ is relatively unequal. Therefore, scale effect should be considered when evaluating public services.

Urban park is increasingly seen as a kind of restricted public resource provided by the city, what's more, cities use high-quality park systems to attract tourists and residents (Paulo et al., 2013), so ensuring its equity should be an important task for city managers (Mu et al., 2019). In this sense, this study provides a useful auxiliary tool in decision-making and also is an important starting point for realizing social equity. The detected relationship between the spatial distribution of urban park service levels and urban population in this case study sheds light into the current situation of urban public service and can offer useful information for improving the equity in urban planning in other cities. In the planning praxis of urban park system, population size and its spatial distribution should be taken into account and be coordinated with the level of service provided by urban parks, in order to achieve a balance between efficiency and equity.

\section{Conclusions}

In this study, the equity of park services was analyzed under two conditions, i.e. without and with consideration of the population distribution. The results show that, when without the consideration of population distribution, the service level of parks in Xiamen is mainly affected by the development history of the city, and the earlier developed area have high service levels. When considering the population distribution, a significant correlation can be seen between population density and park service level. However, this relationship depends on spatial scale. In the whole city, residential communities with high population density generally have a higher level of park service. At a smaller scale this relationship only exists in a part of spatial units investigated.

The results of case analysis show that population- or area-weighted park service level can accurately represent the supply-demand pattern and spatial difference of urban park services. The spatial correlation between urban park service levels and urban population distribution can be used to evaluate the rationality of urban park planning. Although the mechanism remains to be discussed, the linkage between urban park service and urban population can be used as an important indicator to evaluate the performance of urban park and to construct a planning guideline.

\section{Acknowledgements}

This work was financially supported by The National Key R\&D Program of China (2016YFC0502903, 2018YFC0704705, 2018YFC0704703). Tianjin University - Fuzhou University innovation project (TF-1907). Natural Science Foundation of Fujian Province (2019J05037).

\section{References}

Aida, N., Sasidhran, S., Kamarudin, N., Aziz, N., Puan, C. L., \& Azhar, B. (2016). Woody trees, green space and park size improve avian biodiversity in urban landscapes of Peninsular Malaysia. Ecological Indicators, 69, 176-183. https://doi.org/10.1016/j.ecolind.2016.04.025

Boone, C. G., Buckley, G. L., Grove, J. M., \& Sister, C. (2009). Parks and people: An environmental justice inquiry in Baltimore, Maryland. Annals of the Association of American Geographers, 99(4), 767-787. https://doi.org/10.1080/00045600903102949

Brandli, L. L., Prietto, P. D. M., \& Neckel, A. (2015). Estimating the Willingness to pay for improvement of an urban park in Southern Brazil using the contingent valuation method. Journal of Urban Planning and Development, 141(4), A4014001. https://doi.org/10.1061/(ASCE)UP.1943-5444.0000254

Brown, G., Rhodes, J., \& Dade, M. (2018). An evaluation of participatory mapping methods to assess urban park benefits. Landscape and Urban Planning, 178, 18-31.

https://doi.org/10.1016/j.landurbplan.2018.05.018

Chen, Q., Hou, Y., \& Wu, S. (2016). Assessment of accessibility to urban parks in Shaoxing City. Scientia Geographica Sinica, 36, 375-383. https://doi.org/10.13249/j.cnki.sgs.2016.03.008

Chen, W. Y., Hu, F. Z. Y., Li, X., \& Hua, J. Y. (2017). Strategic interaction in municipal governments' provision of public green spaces: A dynamic spatial panel data analysis in transitional China. Cities, 71, 1-10.

https://doi.org/10.1016/j.cities.2017.07.003

Deutscher, J., Kupec, P., Kucera, A., Urban, J., Ledesma, J. L. J., \& Futter, M. (2019). Ecohydrological consequences of tree removal in an urban park evaluated using open data, free software and a minimalist measuring campaign. Science of the Total Environment, 655, 1495-1504. https://doi.org/10.1016/j.scitotenv.2018.11.277 
Donaldson, R., Ferreira, S., Didier, S., Rodary, E., \& Swanepoel, J. (2016). Access to the urban national park in Cape Town: Where urban and natural environment meet. Habitat International, 57, 132-142.

https://doi.org/10.1016/j.habitatint.2016.04.010

Higgs, G., Fry, R., \& Langford, M. (2012). Investigating the implications of using alternative GIS-based techniques to measure accessibility to green space [J]. Environment and Planning B: Planning and Design, 39(2), 326-343. https://doi.org/10.1068/b37130

Ibes, D. C. (2015). A multi-dimensional classification and equity analysis of an urban park system: A novel methodology and case study application. Landscape and Urban Planning, 137, 122-137. https://doi.org/10.1016/j.landurbplan.2014.12.014

Jiang, H. Y., Zhou, C. S., \& Gao, J. B. (2011). Advance in the equity of spatial distribution of urban public service in western countries. City Planning Review, 35, 72-77.

Lee, G., \& Hong, I. (2013). Measuring spatial accessibility in the context of spatial disparity between demand and supply of urban park service. Landscape and Urban Planning, 119, 85-90. https://doi.org/10.1016/j.landurbplan.2013.07.001

Mu, H. K., Gao, Y., Wang, Z. Y., \& Zhang, Y. L. (2019). Equity evaluation of park green space service level from the perspective of supply and demand balance: An empirical analysis based on big Data. Urban Development Studies, 26(11). https://doi.org/10.3969/j.issn.1006-3862.2019.11.012

Paulo, A., Gałaś, A., \& Gałaś, S. (2013). Planning the Colca Canyon and the Valley of the Volcanoes National Park in South Peru. Environmental Earth Sciences, 71, 1021-1032. https://doi.org/10.1007/s12665-013-2506-9

Razak, M. A. W. A., Othman, N., \& Nazir, N. N. M. (2016). Connecting people with nature: Urban park and human well-being. Procedia - Social and Behavioral Sciences, 222, 476-484. https://doi.org/10.1016/j.sbspro.2016.05.138

Rich, R. (1978). Equality and urban policy: The distribution of municipal public services. By Robert L. Lineberry. (Beverly Hills, Calif.: Sage Publications, 1977. Pp. 205. \$11.95, cloth; \$6.00, paper). American Political Science Review, 72(4), 14211423. https://doi.org/10.2307/1954591

Rich, R. C. (1979). Neglected issues in the study of urban service distributions: A research agenda. Urban Studies, 16(2), 143-156. https://doi.org/10.1080/00420987920080221

Rigolon, A. (2016). A complex landscape of inequity in access to urban parks: A literature review. Landscape and Urban Planning, 153, 160-169.

https://doi.org/10.1016/j.landurbplan.2016.05.017

Rigolon, A., Browning, M., \& Jennings, V. (2018). Inequities in the quality of urban park systems: An environmental justice investigation of cities in the United States. Landscape and Urban Planning, 178, 156-169.

https://doi.org/10.1016/j.landurbplan.2018.05.026
Shen, L., Zhang, Z., Zhang, X., Yan, H., \& He, B. (2017). Measuring incoordination-adjusted sustainability performance during the urbanization process: Spatial-dimensional perspectives. Journal of Cleaner Production, 143, 731-743.

https://doi.org/10.1016/j.jclepro.2016.12.050

Smith, J. W., \& Floyd, M. F. (2013). The urban growth machine, central place theory and access to open space. City, Culture and Society, 4(2), 87-98.

https://doi.org/10.1016/j.ccs.2013.03.002

Talen, E., \& Anselin, L. (1998). Assessing spatial equity: An evaluation of measures of accessibility to public playgrounds. Environment and Planning A: Economy and Space, 30(4), 595-613. https://doi.org/10.1068/a300595

Tan, P. Y., \& Samsudin, R. (2017). Effects of spatial scale on assessment of spatial equity of urban park provision. Landscape and Urban Planning, 158, 139-154.

https://doi.org/10.1016/j.landurbplan.2016.11.001

Wüstemann, H., Kalisch, D., \& Kolbe, J. (2017). Access to urban green space and environmental inequalities in Germany. Landscape and Urban Planning, 164, 124-131. https://doi.org/10.1016/j.landurbplan.2017.04.002

Wu, J. S., Si, M. L., \& Li, W. F. (2016). Spatial equity analysis of urban green space from the perspective of balance between supply and demand: A case study of Futian District, Shenzhen, China. Chinese Journal of Applied Ecology, 27(9), 2831-2838. https://doi.org/10.13287/j.1001-9332.201609.011

Xiamen Planning Commision. (2009). Overall urban planning of Xiamen (2010-2020). http://news.xmhouse.com/bd/201501/ t20150130_570993.htm

Xiamen Statistics Bureau. (2015). Yearbook of Xiamen special economic zone. China Statistic Press.

Xiamen Urban Planning and Research Institute. (2015). Xiamen green space system planning.

Xiao, Y., Wang, Z., Li, Z., \& Tang, Z. (2017). An assessment of urban park access in Shanghai - Implications for the social equity in urban China. Landscape and Urban Planning, 157, 383-393. https://doi.org/10.1016/j.landurbplan.2016.08.007

Xie, B., An, Z., Zheng, Y., \& Li, Z. (2018). Healthy aging with parks: Association between park accessibility and the health status of older adults in urban China. Sustainable Cities and Society, 43, 476-486. https://doi.org/10.1016/j.scs.2018.09.010

Yan, H., Wu, F., \& Dong, L. (2018). Influence of a large urban park on the local urban thermal environment. Science of the Total Environment, 622-623, 882-891. https://doi.org/10.1016/j.scitotenv.2017.11.327

Yang, W. Y., Li, X., \& Ye, C. D. (2019). Evaluation Index System for urban green system planning. Planners, 9, 71-76. https://doi.org/10.3969/j.issn.1006-0022.2019.09.012

Yi, L., \& Bai, Z. (2016). A study of recreation behavior and characteristics of Changsha Urban Parks. Journal of Central South University of Forestry \& Technology, 10, 70-73. https://doi.org/10.14067/j.cnki.1673-9272.2016.02.014 